The University of Southern Mississippi

The Aquila Digital Community

Faculty Publications

$5-1-2019$

\title{
Molecular Packing Control Enables Excellent Performance and Mechanical Property of Blade-Cast All-Polymer Solar Cells
}

\author{
Baojun Lin \\ Xi'an Jiaotong University \\ Lin Zhang \\ Xi'an Jiaotong University \\ Heng Zhao \\ Xi'an Jiaotong University \\ Xianbin Xu \\ Xi'an Jiaotong University \\ Ke Zhou \\ Xi'an Jiaotong University
}

See next page for additional authors

Follow this and additional works at: https://aquila.usm.edu/fac_pubs

Part of the Chemistry Commons

\section{Recommended Citation}

Lin, B., Zhang, L., Zhao, H., Xu, X., Zhou, K., Zhang, S., Guo, L., Fan, B., Zhang, L., Yan, H., Gu, X., Ying, L., Huang, F., Cao, Y., Ma, W. (2019). Molecular Packing Control Enables Excellent Performance and Mechanical Property of Blade-Cast All-Polymer Solar Cells. Nano Energy, 59, 277-284.

Available at: https://aquila.usm.edu/fac_pubs/15917

This Article is brought to you for free and open access by The Aquila Digital Community. It has been accepted for inclusion in Faculty Publications by an authorized administrator of The Aquila Digital Community. For more information, please contact Joshua.Cromwell@usm.edu. 


\section{Authors}

Baojun Lin, Lin Zhang, Heng Zhao, Xianbin Xu, Ke Zhou, Song Zhang, Lu Guo, Baobing Fan, Lei Zhang, Hongping Yan, Xiaodan Gu, Lei Ying, Fei Huang, Yong Cao, and Wei Ma 


\title{
Molecular packing control enables excellent performance and mechanical property of blade-cast all-polymer solar cells
}

\author{
Baojun Lin ${ }^{\mathrm{a}}$, Lin Zhang ${ }^{\mathrm{a}}$, Heng Zhao ${ }^{\mathrm{a}}$, Xianbin Xu' ${ }^{\mathrm{a}}$, Ke Zhou ${ }^{\mathrm{a}}$, Song Zhang ${ }^{\mathrm{b}}$, Lu Gou ${ }^{\mathrm{c}}$, \\ Baobing Fan ${ }^{\mathrm{d}}$, Lei Zhang ${ }^{\mathrm{c}}$, Hongping Yan ${ }^{\mathrm{e}}$, Xiandan $\mathrm{Gu}^{\mathrm{b}, *}$, Lei Ying ${ }^{\mathrm{d}}$, Fei Huang ${ }^{\mathrm{d}, *}$, Yong Cao ${ }^{\mathrm{d}}$, \\ Wei $\mathrm{Ma}^{\mathrm{a}, \mathrm{d}, *}$ \\ ${ }^{a}$ State Key Laboratory for Mechanical Behavior of Materials, Xi'an Jiaotong University, Xi'an 710049, China \\ ${ }^{\mathrm{b}}$ School of Polymer Science and Engineering, the University of Southern Mississippi, Hattiesburg, MS 39406, USA \\ 'Shaanxi Province Key Laboratory of Quantum Information and Quantum Optoelectronic Devices, School of Science, Xi'an Jiaotong University, Xi'an 710049, China \\ ${ }^{d}$ State Key Laboratory of Luminescent Materials and Devices, South China University of Technology, Guangzhou 510640, China \\ ' SLAC National Accelerator Laboratory, Menlo Park, CA 94025, USA
}

\section{A R T I C L E I N F O}

Keywords:

All-polymer organic solar cells

Blade-coating

Mechanical property

Molecular packing

\begin{abstract}
A B S T R A C T
All-polymer solar cells (all-PSCs) are the most promising power generators for flexible and portable devices due to excellent morphology stability and outstanding mechanical property. Previous work indicates high crystallinity is beneficial to device performance but detrimental to mechanical property, therefore identifying the optimized ratio between crystalline and amorphous domains becomes important. In this work, we demonstrated highly efficient and mechanically robust all-PSCs by blade-coating technology in ambient environment based on PTzBI:N2200 system. By controlling the aggregation in solution state and ultrafast film formation process, a weakly ordered molecular packing morphology as well as small phase separation is obtained, which leads to not only the good photovoltaic performance $(8.36 \%$-one of the best blade-cast device in air) but also prominent mechanical characteristic. The controlled film shows a remarkable elongation with the crack onset strain of $15.6 \%$, which is the highest result in organic solar cells without adding elastomers. These observations indicate the great promise of the developed all-PSCs for practical applications toward large-area processing technology.
\end{abstract}

\section{Introduction}

Organic solar cells (OSCs) have attracted extensive attentions due to their great potential to be applied in flexible electronics in consideration of their superior merits of flexibility, wearability and roll-to-roll processibility [1-4]. Compared to fullerene- and small molecular-based OSCs, all-polymer solar cells (all-PSCs), composed of a pair of conjugated polymer donor and acceptor, have shown their intrinsic advantages including low-cost production, facile modification of the absorption and energy level, good morphological stability and excellent mechanical property [5-12]. Great progress has been made to boost the power conversion efficiency (PCE) of all-PSCs from 2\% to $8-10 \%$ [13-19] in binary systems, but the PCE still lags behind that of state-ofthe-art fullerene- and small molecular-based OSCs [20]. Among the reported polymer acceptors [14,17-19,21-24], naphthalene diimide (NDI)-based copolymers, for instance, poly $\{[\mathrm{N}, \mathrm{N}-9-\mathrm{bis}(2-\mathrm{octyldodecyl})-$ naphthalene-1,4,5,8-bis(dicarboximide)-2,6-diyl]-alt-5, 5'-(2,2'-bithiophene)\} [P(NDI2OD-T2); Polyera ActivInk N2200] are the most well- known polymer acceptors which exhibit good electron affinity and high electron mobility [12] because of their strong intermolecular $\pi-\pi$ interaction and well-stacked $\pi$-conjugated structure [25-27]. The strong intermolecular interaction leads to enhanced molecular packing in solid films. The highly ordered packing of N2200 reduces its miscibility with donor, leading to the large domain size beyond the exciton diffusion length which is disadvantageous to charge transport [28-31]. Therefore, controlling the crystallinity and molecular packing is indispensable for N2200-based all-PSCs.

To be commercially available, a primary challenge of the all-PSCs is the large-area processing. Previously reported high-efficiency all-PSCs are mostly prepared by spin-coating in nitrogen atmosphere, which cannot be extended to large-area production. As an alternative, bladecoating (as shown in Fig. 1a) can be compatible with large-area roll-toroll coating [32-34]. It has been reported that the morphology and drying dynamics of films processed by blade-coating and spin-coating are different due to the intrinsic properties of blade-coating, such as anisotropic stress and high shearing force [35,36]. Therefore,

\footnotetext{
* Corresponding authors.

E-mail addresses: xiaodan.gu@usm.edu (X. Gu), msfhuang@scut.edu.cn (F. Huang), msewma@xjtu.edu.cn (W. Ma).
} 

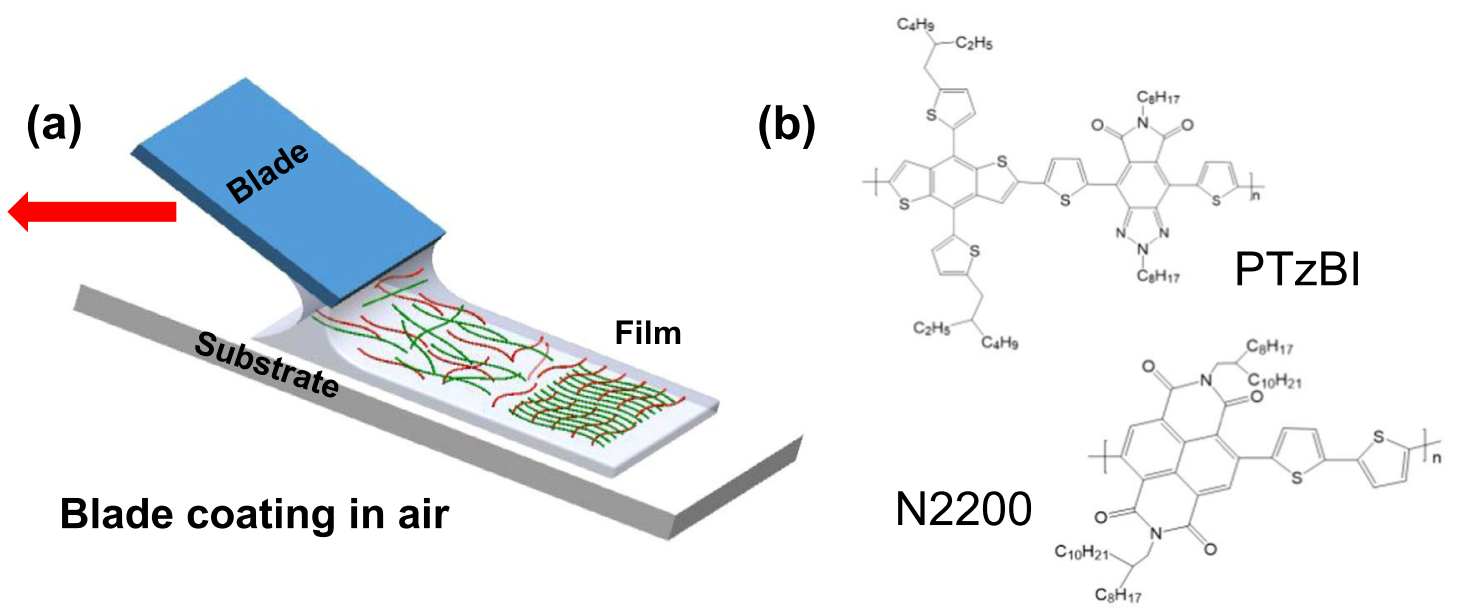

(c)

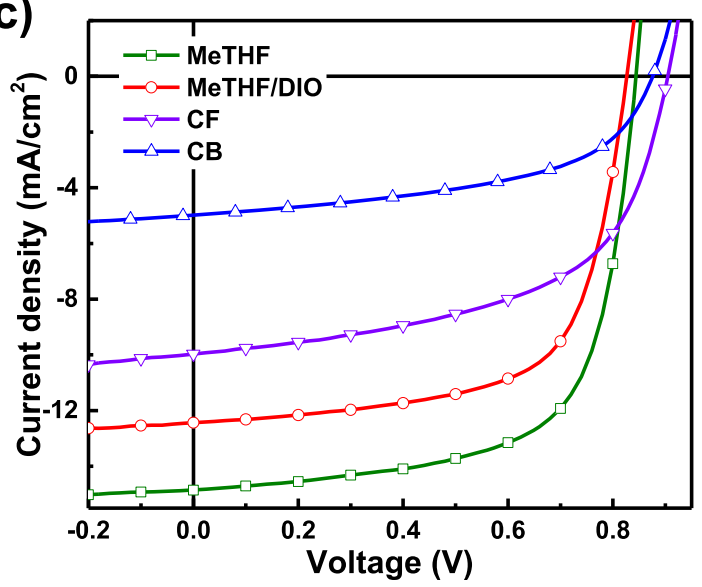

(e)

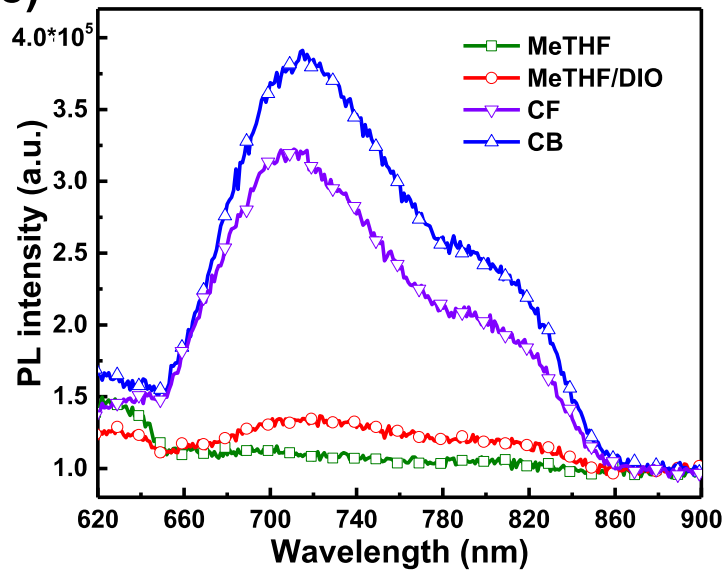

(d)

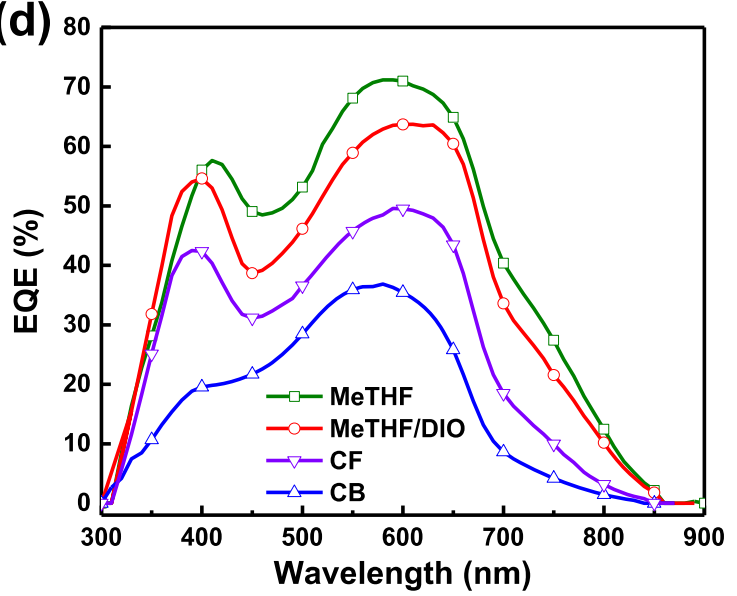

(f)

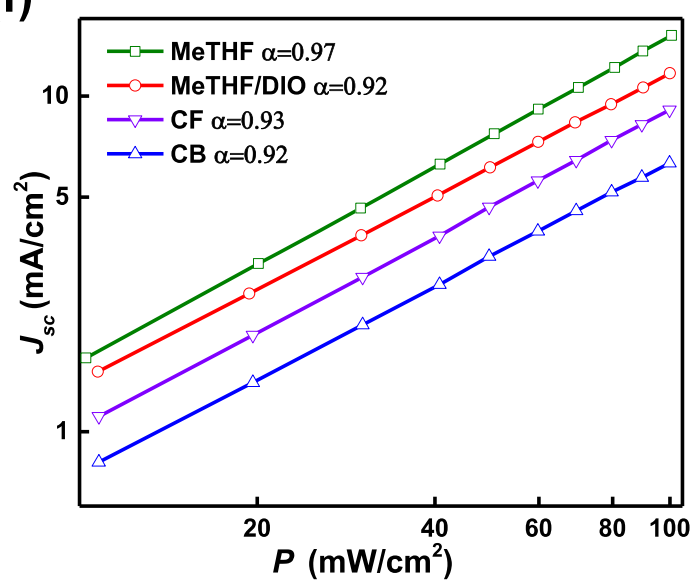

Fig. 1. a) Schematic diagram of blade-coating. b) Chemical structures of PTzBI and N2200. c) $J-V$ curves, d) EQE curves, e) photoluminescence spectra and f) dependence of the short circuit current density on light density of blade-coating films processed from different solvents.

morphology optimization of blade-coated films will be different from the spin-coated films. Bao and coworkers have indicated that the degree of molecular packing in neat polymer films can be changed by altering the shearing speed [37] and we have reported blade-coated films show higher domain purity than spin-coated films in small molecule-based OSCs [38]. However, the majority of existing literature about bladecoated films are based-on polymer neat film, polymer: fullerene and polymer: small molecular blend films. For the all-PSCs, Hou et al. [39] have reported blade-coated PTB7-Th:PNDI-T10 system by incorporating an additive to rearrange polymer chains to control the phase separation. Similar reports about blade-coating all-PSCs are infrequent and the morphology control of all-PSCs by blade-coating should be further explored.

To achieve good flexibility and extend the application of all-PSCs, their mechanical property should be further studied. Great progresses have been made to characterize the mechanical property of $\sim 100 \mathrm{~nm}$ semiconducting polymer films. To eliminate the influence of substrate and measure stress-strain response in free-standing thin films directly, Kim and co-workers [40] developed a "pseudo free-standing thin-film tensile test" method, imitating the traditional mechanical tensile test. Using this method, several reports have illustrated that all-PSCs exhibit much better mechanical strength than fullerene-based OSCs because of 
the higher inherent ductility of polymers than fullerenes and the reinforced interfaces by the entanglement between polymer chains [11,41-43]. However, how to enhance the mechanical property of allPSCs with high photovoltaic performance remains unexplored. Kim [11] et al. have revealed that crystallinity has great influence on the mechanical property of semiconductor thin films. The increased crystallinity restricts the movement of polymer chain and makes the film more brittle and stiffer to fracture, which exhibits higher tensile modulus and lower crack onset strain (COS). Considering the relationship between device performance and molecular packing, high photovoltaic performance and mechanical property seem to be consistent in N2200based all-PSCs which can be achieved by decreasing crystallinity of polymers. However, there is no reported strategy on morphology optimization in all-PSCs to achieve optoelectronic performance and mechanical property simultaneously by blade-coating.

Herein, we fabricated high-efficient, malleable all-PSCs via bladecoating method by carefully regulating the solution thermodynamics and film formation kinetics. High performance and mechanically robust devices are fabricated by using poly\{4,8-bis(5-(2-ethylhexyl)thiophen2-yl)benzo[1,2-b:4,5-b']dithiophene-co-4,8-di(thien-2-yl)-6-octyl-2octyl-5H-pyrrolo[3,4-f]benzotriazole-5,7(6H)-dione\}(PTzBI) as the electron donor and N2200 as the electron acceptor [15]. Various solvents were introduced in the all-PSCs to control the aggregation of N2200 in solution and the film drying dynamics. N2200 shows stronger aggregation in 2-Methyltetrahydrofuran (MeTHF) solvent and transforms into film quickly which restrains the growth of aggregates, leading to weaker crystallization. Thus, the blade-coated all-PSCs based on MeTHF solvent exhibits higher PCE of $8.36 \%$. Moreover, the MeTHFprocessed film shows a much higher COS of $15.6 \%$ than those of chloroform (CF)- and chlorobenzene (CB)-processed films $(8.1 \%$ and $6.3 \%$ ), indicating the excellent mechanical characteristic of MeTHFprocessed film. The morphology characterizations indicate that the controlled film shows the weakest crystallization which explains the better ductility and PCE. In addition, the smaller phase separation and isotropic packing in controlled film is also responsible for the better device performance.

\section{Results and discussion}

The chemical structures of PTzBI and N2200 are shown in Fig. 1b. Bulk-heterojunction was fabricated with an inverted device structure of ITO/ZnO/PTzBI:N2200/ $/ \mathrm{MoO}_{\mathrm{x}} / \mathrm{Al}$, and various solvents, MeTHF, MeTHF/1,8-diiodooctane (DIO), CF and CB were used to dissolve the polymers. The current density-voltage characteristics of corresponding blade-coated devices are shown in Fig. 1c and the photovoltaic parameters are summarized in Table 1 . The blade-coated device prepared from MeTHF displays the best photovoltaic performance with the opencircuit voltage $\left(V_{\mathrm{oc}}\right)$ of $0.84 \mathrm{~V}$, the short-circuit current density $\left(J_{\mathrm{sc}}\right)$ of $14.86 \mathrm{~mA} / \mathrm{cm}^{2}$, the fill factor (FF) of $66.65 \%$ and the resulted power conversion efficiency (PCE) of $8.36 \%$, which is one of the best devices fabricated in air with blade-coating. When the solvents were changed to MeTHF/DIO, CF and CB, the device performance got worse due to the reduced $J_{s c}$ and FF. The external quantum efficiency (EQE) curves (Fig. 1d) shows two bands at $350-450 \mathrm{~nm}$ and $450-700 \mathrm{~nm}$, corresponding to the absorption of N2200 and PTzBI (Fig. S1), respectively.
Devices prepared from MeTHF show much higher EQE in whole spectrum range with the largest $\mathrm{EQE}$ of $71 \%$, which is responsible for the larger $J_{s c}$.

To investigate the exciton dissociation and charge transfer behavior in the polymer blends, photoluminescence (PL) spectrum (Fig. 1e) of polymer blends were measured. According to the absorption spectra of the PTzBI and N2200 pure film (Fig. S1), there is an absorption band in $450-700 \mathrm{~nm}$ for the PTzBI film, and there are two absorption bands in the range of $300-425 \mathrm{~nm}$ and $600-850 \mathrm{~nm}$ for N2200 film, thus the wavelength of $590 \mathrm{~nm}$ was used to solely excite PTzBI. The PL emission is in the range of $640-860 \mathrm{~nm}$ with a peak at $710 \mathrm{~nm}$. Excitons in MeTHF-processed polymer blends are almost completely quenched by the N2200 in blends, while MeTHF/DIO-, CF- and CB-processed films show higher PL intensity. The results indicate that the exciton dissociation and charge transfer between PTzBI and N2200 in MeTHFprocessed film are highly efficient while in other solvents-processed films are not efficient, which further explains the variation of $J_{s c}$ and FF when processed from different solvents.

Light-intensity dependence of photovoltaic performance of the allPSCs prepared from different solvents was further investigated to illustrate recombination behavior in devices [44-50]. In general, $J_{s c}$ has a power-law dependence on light intensity $\left(J_{s c} \propto P^{\alpha}\right)$, where power-law component $\alpha$ should be close to unity when the bimolecular recombination is negligible [45]. As shown in Fig. 1f, the fitted $\alpha$ value for MeTHF-processed device is 0.97, while those values of MeTHF/ DIO-, CF- and CB-processed devices are almost the same $(0.92,0.93$, $0.92)$ but lower than that of MeTHF-processed device. The remarkable higher $\alpha$ value indicates the bimolecular recombination is restrained effectively in the MeTHF-processed device. The dependence of $V_{o c}$ on light intensity exhibits linear relationships with a slope of kT/q, which reveals the Shockley-Read-Hall (SRH) recombination [45,46]. According to Fig. S2, the calculated slope of MeTHF-processed device is $1.26 \mathrm{kT} / \mathrm{q}$ which is lower than those of MeTHF/DIO-, CF- and CBprocessed devices, suggesting a lower SRH recombination than devices processed from other solvents.

To study the effects of processing solvents on the charge carrier mobility, hole mobility $\left(\mu_{h}\right)$ and electron mobility $\left(\mu_{e}\right)$ were measured by space-charge limited current (SCLC) method using hole-only device of ITO/PEDOT: PSS/PTzBI:N2200/ $\mathrm{MoO}_{\mathrm{x}} / \mathrm{Al}$ and electron-only device of ITO/ZnO/PTzBI:N2200/Ca/Al [51,52]. As shown in Fig. S3 and Table 1, the MeTHF-processed device showed the highest hole and electron mobility $\left(\mu_{h}=6.10 \times 10^{-4} \mathrm{~cm}^{2} \mathrm{~V}^{-1} \mathrm{~S}^{-1}\right.$ and $\mu_{e}=1.22 \times 10^{-4}$ $\mathrm{cm}^{2} \mathrm{~V}^{-1} \mathrm{~S}^{-1}$ ). These values were significantly higher than those of the MeTHF/DIO, CF and CB-processed devices $\left(\mu_{h} / \mu_{e}\right.$ values of $2.60 \times 10^{-4} /$ $1.14 \times 10^{-5} \mathrm{~cm}^{2} \mathrm{~V}^{-1} \mathrm{~S}^{-1}, 5.62 \times 10^{-5} / 8.95 \times 10^{-6} \mathrm{~cm}^{2} \mathrm{~V}^{-1} \mathrm{~S}^{-1}$ and $1.14 \times 10^{-5} / 8.90 \times 10^{-6} \mathrm{~cm}^{2} \mathrm{~V}^{-1} \mathrm{~S}^{-1}$ ). The higher and relatively balanced charge carrier mobility agrees well with the device performance and recombination results.

The tensile parameters were measured to acquire a quantitative comparison of the mechanical property of the all-polymer blend films by using the pseudo free-standing tensile test (Fig. 2a), in which the prepared dog-bone shaped film was stretched on the water surface to rule out the disturbance from solid substrate. As a result, the intrinsic mechanical parameters, such as tensile modulus and crack onset strain, were directly measured without complicated calculations. The

Table 1

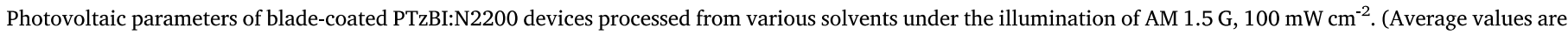
obtained from 10 devices).

\begin{tabular}{|c|c|c|c|c|c|c|c|c|}
\hline Solvent & $V_{o c}(\mathrm{~V})$ & $J_{s c}\left(\mathrm{~mA} \mathrm{~cm}^{-2}\right)$ & $J_{E Q E}\left(\mathrm{~mA} \mathrm{~cm}^{-2}\right)$ & $F F(\%)$ & PCE (\%) & $\mathrm{PCE}_{\text {avg }}(\%)$ & $\mu_{h}\left(\mathrm{~cm}^{2} \mathrm{~V}^{-1} \mathrm{~S}^{-1}\right)$ & $\mu_{e}\left(\mathrm{~cm}^{2} \mathrm{~V}^{-1} \mathrm{~S}^{-1}\right)$ \\
\hline MeTHF & 0.84 & 14.86 & 14.15 & 66.65 & 8.36 & $8.03 \pm 0.20$ & $6.10 \times 10^{-4}$ & $1.22 \times 10^{-4}$ \\
\hline MeTHF/DIO & 0.83 & 12.43 & 11.97 & 65.93 & 6.78 & $6.47 \pm 0.20$ & $2.60 \times 10^{-4}$ & $1.14 \times 10^{-5}$ \\
\hline $\mathrm{CF}$ & 0.90 & 9.05 & 8.76 & 55.43 & 4.49 & $4.37 \pm 0.10$ & $5.62 \times 10^{-5}$ & $8.95 \times 10^{-6}$ \\
\hline $\mathrm{CB}$ & 0.89 & 6.23 & 6.12 & 52.99 & 2.92 & $2.63 \pm 0.16$ & $1.14 \times 10^{-5}$ & $8.90 \times 10^{-6}$ \\
\hline
\end{tabular}


(a)

Load Stage

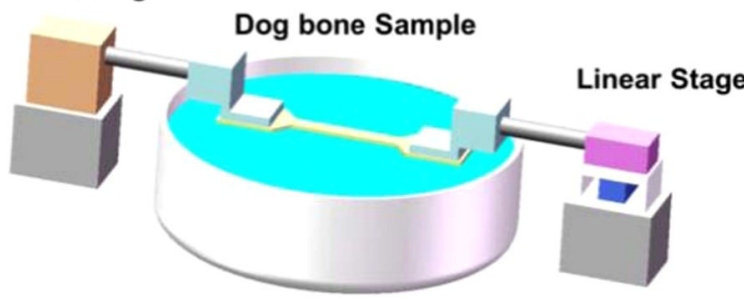

(b)

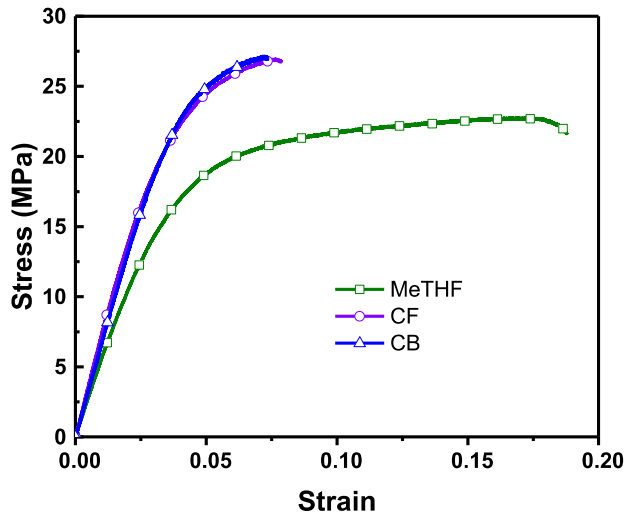

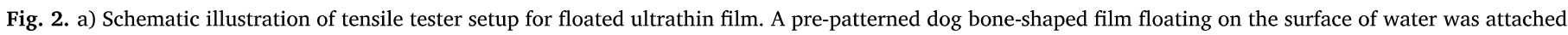
by two aluminum grips coated with silicone rubber. b) Stress-strain curves of films processed with MeTHF, CF and CB solvents.

Table 2

Average tensile modulus and average COS of PTzBI:N2200 films processed from various solvents. Each data point is calculated from a minimum of four samples.

\begin{tabular}{lllll}
\hline Solvent & Avg. Modulus (MPa) & Error (MPa) & Avg. COS & Error \\
\hline MeTHF & 517.2 & 50.3 & 0.156 & 0.034 \\
CF & 701.9 & 46.0 & 0.081 & 0.018 \\
CB & 620.6 & 51.0 & 0.063 & 0.011 \\
\hline
\end{tabular}

stress-strain curves are shown in Fig. $2 \mathrm{~b}$ and the mechanical parameters are summarized in Table 2 . The curves consist of three regions, including elastic, yield and plastic deformation region. The CF- and CBprocessed films show no obvious plastic deformation region and break at a short elongation, while the MeTHF-processed film exhibits a wide deformation and cracks at a much longer elongation. The elastic modulus of CF- and CB-processed film are calculated to be 701.9 and 620.6 MPa, higher than that of MeTHF processed film (517.2 MPa). The larger elastic modulus indicates a brittler film which is not favorable to the application of flexible OSCs. The CF- and CB-processed films rupture after yielding and show a lower COS of $8.1 \%$ and $6.3 \%$, respectively. In contrast, the MeTHF-processed film shows a remarkable plastic deformation with a COS of $15.6 \%$, about twice as those of CF and $\mathrm{CB}$ processed films. The curve shape of the $\mathrm{CF}$ and CB-processed films manifests strong crystallization while the shape of MeTHF-processed film indicates weak crystallization or small grains [53,54], thus differences in mechanical property may be due to the morphology caused by the various solvents. The superior mechanical property of MeTHF-processed all-polymer films provide promising prospects to be applied in flexible and stretchable electronics that requires great tolerance to mechanical deformation $[55,56]$. To the best of our knowledge, it should be the highest elongation of reported OSCs polymer blends without adding elastomers.

Grazing incident wide angle X-ray scattering (GIWAXS) [57] was carried out to account for the correlation between molecular packing in films processed from various solvents and device performance. The twodimensional GIWAXS patterns and one-dimensional profiles of bladecoated pure donor and acceptor films are shown in Figs. S4 and S5. The pure PTzBI films processed from different solvents have an obvious $(010)$ peak $\left(q \approx 1.71 \AA^{-1}\right)$ in the out-of-plane direction and (100) peak $\left(q \approx 0.29 \AA^{-1}\right)$ in the in-plane direction, which indicates a preferential face-on orientation. As summarized in Table S1, PTzBI pure film processed by MeTHF displays a slightly larger coherence length (CL) than those of CB- and CF-processed films while the use of DIO enhances the $\pi-\pi$ stacking of PTzBI notably. The pure N2200 film also displays a face-on orientation with an out-of-plane $(010)$ peak $\left(q \approx 1.59 \AA^{-1}\right)$ and in-plane $(100)$ peak $\left(q \approx 0.25 \AA^{-1}\right)$. CF-processed N2200 pure film shows strongest $\pi-\pi$ stacking and CB-processed film shows weaker stacking while MeTHF-processed N2200 film exhibits the weakest crystallization while DIO plays a weak effect on the stacking of N2200.

Two-dimensional GIWAXS patterns and one-dimensional profiles of polymer blends are shown in Fig. 3a and b. Both PTzBI and N2200 maintain their orientations in blends. The out-of-plane $(010)$ peaks and in-plane (100) peaks are formed by combining the donor and acceptor peaks while the peak at $q \approx 0.45 \AA^{-1}$ is assigned to (001) of N2200. The $(010)$ peaks can be divided into two peaks by Gaussian function fitting (as shown in Fig. S7) according to the crystal parameters of pure films and the results are concluded in Table 3. MeTHF-processed film shows the smallest CL $(1.19 \mathrm{~nm})$ which indicates the weak crystallization of N2200. CL of CF- and CB-processed film increases to $1.40 \mathrm{~nm}$ and $1.75 \mathrm{~nm}$. Meanwhile, the crystallization of PTzBI is almost the same when processed from different solvents. Thus we conclude that the weak crystallization of N2200 results in better photovoltaic performance in the MeTHF-processed device. The (001) CL shows the similar tendency as the solvents changed that MeTHF-processed film shows the smallest CL and CB-processed film shows the largest CL. According to previous literature, the increased lamellar stacking is not beneficial to the charge transfer in N2200 domains [58]. The relatively better performance of MeTHF/DIO-processed film is attributed to the increased crystallization of amorphous donor. The (100) peak can't be divided into two peaks except the CB-processed film while MeTHF-processed film shows the weakest lamellar stacking. The segregative (100) peak of CB-processed film and the fitted CL reveal the poor miscibility of PTzBI and N2200 in CB solvents, and strong lamellar stacking results in large phase separation and poor performance. Devices processed from $\mathrm{CF}$ and CB solvents show worse performance, which may be attributed to the larger domain size caused by the strong crystalinity. The spin-coated films show the similar crystallization behavior but stronger than those of corresponding blade-coated films, as shown in Fig. S6 and Table S2.

The morphology of the PTzBI:N2200 blend films processed from various solvents were further characterized by transmission electron microscopy (TEM) (Fig. 3c-f). In the image of the MeTHF-processed film (Fig. 3c), a disordered structure can be seen while for MeTHF/DIOprocessed film (Fig. 3d) a relatively higher ordered chains can be observed. For CF-, CB-processed films (Fig. 3e and $\mathrm{f}$ ), the periodic structure of the stacked chains are visible. From the inset Fourier transforms images, all the films show at least one circle which corresponds to the $\mathrm{q}$ vector consistent with the (100) peaks obtained from GIWAXS characterization, confirming the face-on orientation of polymer chains. No obvious (001) circle can be seen in the MeTHF processed film (Fig. 3c), indicating the weak backbone ordering. MeTHF/DIO-processed film shows fuzzy and negligible (001) circle, which coincides with the GIWAXS results of N2200 films that DIO has faint effect on N2200 backbone stacking. For CF-, CB-processed film, a clear (001) circle can be seen, manifesting the strong backbone stacking. Meanwhile, the (100) circle of MeTHF-processed film is round while that of MeTHF/ DIO-, CF, CB-processed film is elliptical, declaring the anisotropic 

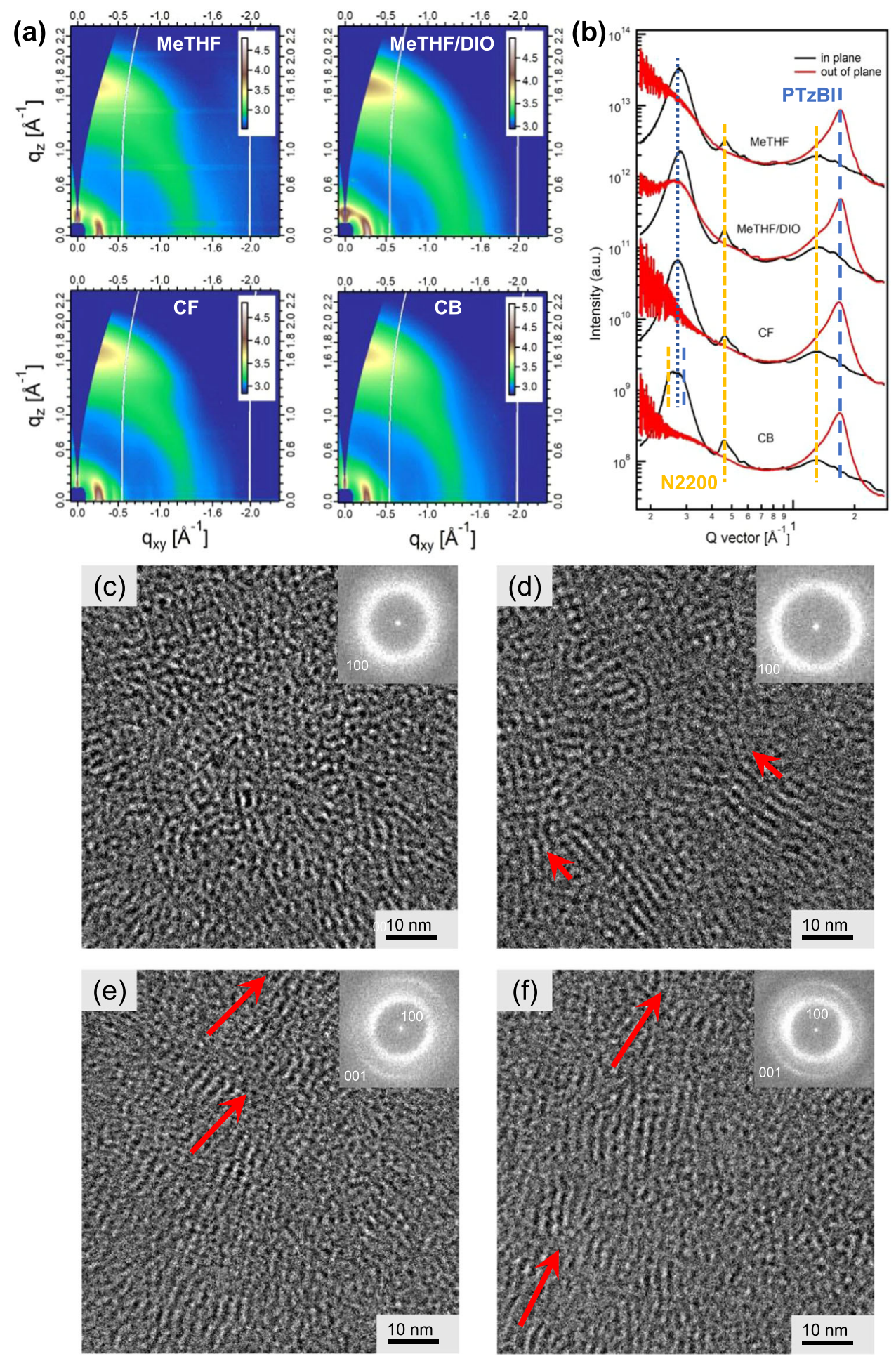

Fig. 3. a) 2D GIWAXS patterns, b) line profiles of PTzBI:N2200 blade-coating films processed from various solvents and TEM images of PTzBI:N2200 blade-coating films processed from various solvents c) MeTHF, d) MeTHF/DIO, e) CF and f) CB. The Fourier transform of the image, in the inset, shows two periodic features corresponding to the (100) and the (001) stacking directions. The arrows in d-f show the local orientation of films.

packing when processed from MeTHF/DIO, CF and CB solvents. The distance of two rod-like objects were measured to be about $2.2 \mathrm{~nm}$, which is equal to the lamellar stacking distance calculated from GIWAXS results. Thus, we inferred that the rod-like objects shown in these images is the backbone chain of polymer. In consideration of the device performance, it seems that the anisotropic packing does harm to the photovoltaic performance.

To illustrate the isotropic orientation and different phase separation in MeTHF-processed film, the solution state was taken into consideration. Fig. 4a shows the absorption spectra of N2200 in the different solvents. The normalized UV-vis absorption spectra are characterized by a $\pi-\pi^{*}$ band with a peak at $\approx 390 \mathrm{~nm}$ and a lower energy band between 500 and $800 \mathrm{~nm}$ associated with charge-transfer excitation [59]. N2200 in $60^{\circ} \mathrm{C}$ MeTHF and MeTHF/DIO solution shows similar absorption while in the room temperature $\mathrm{CF}$ and $40^{\circ} \mathrm{C} \mathrm{CB}$ solution shows similar but relatively lower absorption. The strong absorption in 
Table 3

Structural parameters obtained by fitting the GIWAXS profiles for the PTzBI:N2200 films processed from different solvents by blade-coating.

\begin{tabular}{|c|c|c|c|c|c|}
\hline & Solvent & d-spacing $(\AA)$ & CL (nm) & d-spacing ( & CL (nm) \\
\hline In plane & MeTHF & 22.76 & 10.33 & & \\
\hline \multirow[t]{3}{*}{$(100)$} & MeTHF/DIO & 22.58 & 12.00 & & \\
\hline & $\mathrm{CF}$ & 23.25 & 11.23 & & \\
\hline & $\mathrm{CB}$ & 22.73 & 10.92 & 25.40 & 19.53 \\
\hline In plane & MeTHF & 13.56 & 14.30 & & \\
\hline \multirow[t]{3}{*}{$(001)$} & MeTHF/DIO & 13.70 & 14.90 & & \\
\hline & $\mathrm{CF}$ & 13.63 & 15.43 & & \\
\hline & $\mathrm{CB}$ & 13.81 & 16.29 & & \\
\hline Out of plane & MeTHF & 3.95 & 1.19 & 3.66 & 2.63 \\
\hline \multirow[t]{3}{*}{$(010)$} & MeTHF/DIO & 3.95 & 2.15 & 3.65 & 3.06 \\
\hline & $\mathrm{CF}$ & 3.95 & 1.40 & 3.72 & 2.52 \\
\hline & $\mathrm{CB}$ & 3.95 & 1.75 & 3.68 & 2.65 \\
\hline
\end{tabular}

MeTHF solution implicates the strong aggregation. We further measured the solubility of N2200 in different solvents by diluting the concentrated solution stepwise and summarized in Table S3 [15]. In MeTHF, N2200 shows a low solubility of $7 \mathrm{mg} / \mathrm{mL}$ while in CF and CB a high solubility of $35 \mathrm{mg} / \mathrm{mL}$ and $30 \mathrm{mg} / \mathrm{mL}$ are exhibited, respectively. Thus the large diversity of solubility may explain the strong aggregation in MeTHF. In addition, PTzBI shows a good solubility in all three solvents.

According to the literature, similar disordered packing shown in Fig. 3c was seen in N2200 film processed from chloronaphthalene: xylene solvent [58]. However, N2200 shows strong aggregation but weak crystallization in MeTHF. To better understand the molecular packing dependence on solvents, in-situ GIWAXS was used to probe kinetics process during blade-coating and the (100) peaks were chosen to analyze the morphology evolution due to the negligible interference from solvent peaks. Owing to the short exposure time and low intensity, it's hard to separate the (100) peaks into donor and acceptor peaks even in CB-processed film. According to the literature, film formation process ends when the peak location remains unchanged [60]. As shown in Fig. 4b, the locations of CF, MeTHF-processed films get balanced very quickly within ten seconds due to the low boiling point of $\mathrm{CF}$ and MeTHF $\left(60^{\circ} \mathrm{C}\right.$ and $80^{\circ} \mathrm{C}$, respectively), resulting in an ultrafast film formation process under certain conditions. The rapid evaporation of the solvent makes the molecular segments have little time to line up, leading to the weak molecular packing. The use of DIO can slightly delay the onset of film formation and postpone the swelling stage owing to its high boiling point $\left(332^{\circ} \mathrm{C}\right)$. The inset in Fig. $4 \mathrm{~b}$ shows that location in MeTHF/DIO-processed film grows slowly until $180 \mathrm{~s}$, revealing the shrinking d-spacing between chains with the volatilization

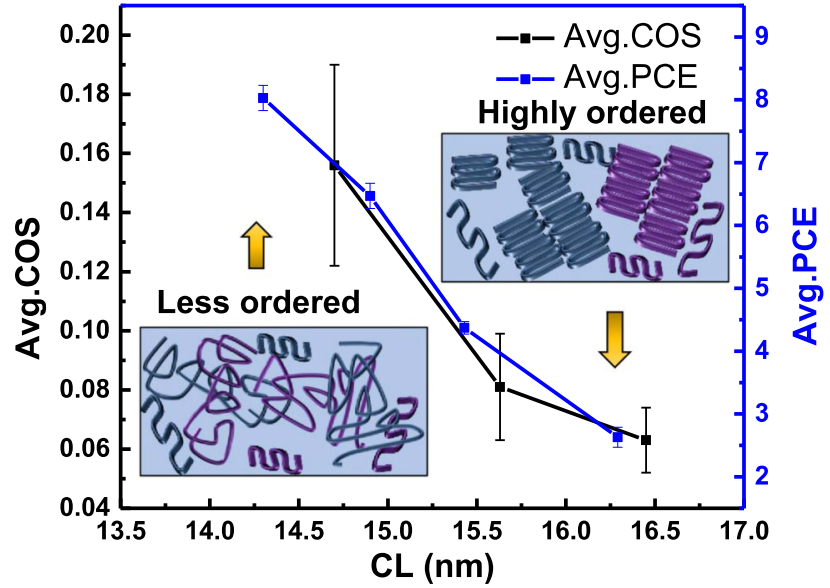

Fig. 5. Average COS and Average PCE dependence on (001) CL values calculated from GIWAXS data.

of residual solvent between chains. In contrast, the CB-processed film shows a much delayed onset until $30 \mathrm{~s}$ because of the tardy volatilization of high boiling point solvent $\mathrm{CB}\left(132^{\circ} \mathrm{C}\right)$, making it hard to reach the saturation limit. The prolonged film formation process ensures enough time for N2200 to crystallize and give rise to the strong packing along three crystallographic axes. For the MeTHF solution, when the high temperature solution touches the low temperature substrate during blade-coating, the solubility of N2200 in MeTHF drops rapidly and N2200 begins to nucleate but has no impetus to achieve chain rearrangement and crystallization. The quick evaporation of MeTHF suppresses the further growth of crystalline grains. As a result, a disorder and isotropic morphology of MeTHF-processed film was exhibited.

The relationships among device performance, mechanical property and crystallization are summarized in Fig. 5. (001) CL represents the crystallization of N2200 in different films. With the increase of (001) CL value, the average device performance and mechanical property get worse. Considering the GIWAXS and TEM data, the weaker molecular packing and smaller crystal grains or domains lead to the lower tensile modulus and larger COS value, which coincidences with the previous literature, while the smaller COS value of CF- and CB-processed film is in agreement with the strong crystallization and large domains. By decreasing the order of N2200 molecular packing, device performance and mechanical property can be improved simultaneously in bladecoated all-PSCs.

\section{(a)}

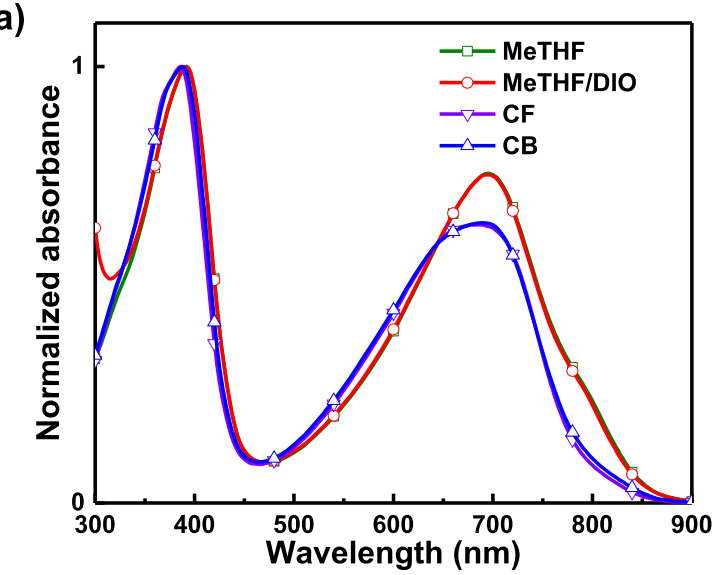

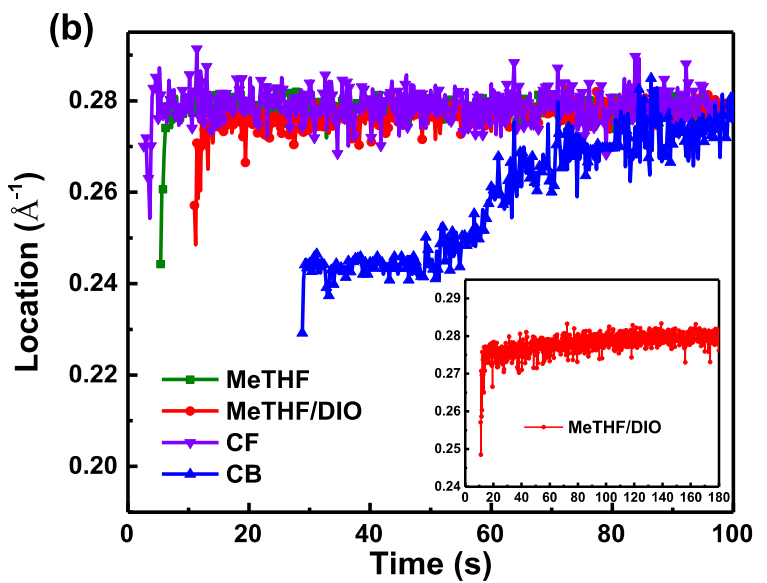

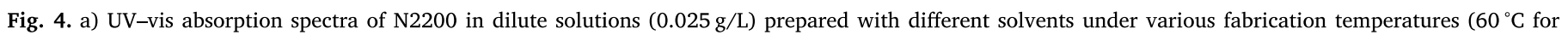

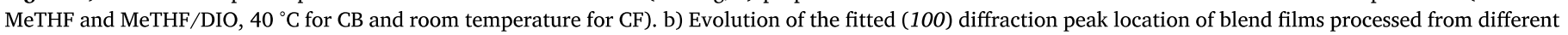
solvents. The inset shows the detailed location variation of MeTHF/DIO-processed film. 


\section{Conclusion}

In conclusion, we fabricated efficient and ductile PTzBI:N2200 devices by blade-coating in ambient environment. A high PCE of $8.36 \%$ was achieved by using non-halogen solvent of MeTHF, which has low boiling point and poor solubility of N2200. N2200 shows strong aggregation in MeTHF solvent and begins to nucleate quickly when the solution is dropped on the relatively cold plate because of the low solubility. The low boiling point inhibits the further growth of nucleation. Thus a low crystallinity and small grain size morphology are obtained. Our results suggest the control of N2200 crystallization can be achieved by adjusting the solution state and film formation process by blade coating. The lower crystallization of N2200 and smaller phase separation determine the better performance of MeTHF-processed device. We further find the MeTHF-processed film shows ductile mechanical property with a low modulus tensile of only $517.2 \mathrm{MPa}$ and a large elongation of $15.6 \%$, which are attributed to the weak crystallinity and isotropic molecular packing, while the CF- and CB-processed film exhibits stiff and brittle mechanical characteristic. The superior electronic and mechanical device performance with large-area fabrication technique provides rosy prospects of the application of OSCs. Our results provide helpful information for all-PSCs transferring from the lab-scale research to practical use which requires both high photovoltaic performance and mechanical robustness.

\section{Experiment section}

\subsection{Materials}

PTzBI and N2200 were provided by Fei Huang's Group. All chemicals used as received without further purification. $\mathrm{ZnO}$ precursor was prepared by dissolving zinc acetate in 2-Methoxyethanol with Ethanolamine [61].

\subsection{Device fabrication}

BHJ organic solar cells were fabricated with an inverted device architecture of ITO/ZnO/PTzBI:N2200/MoOx/Al. The pattered ITO substrate was sequential cleaned by sonication in detergent water, deionized water, acetone and isopropanol for $20 \mathrm{~min}$ of each steps. After UVO treatment for $20 \mathrm{~min}$, ZnO precursor was spin-coated on the cleaned ITO substrate to form a $40 \mathrm{~nm}$ electron-transporting layer, followed by thermal annealing at $200{ }^{\circ} \mathrm{C}$ for $30 \mathrm{~min}$. The active layer solution was prepared at a total concentration of $7.5 \mathrm{mg} / \mathrm{mL}$ (D:A, $2: 1$ by weight) with various solvents (MeTHF, MeTHF/1\%DIO, CF and CB). MeTHF and MeTHF/DIO solution was stirred on $80^{\circ} \mathrm{C}$ hotplate while CF and $\mathrm{CB}$ solution was stirred on $50^{\circ} \mathrm{C}$ hotplate. Then, $\mathrm{a} \approx 100 \mathrm{~nm}$ film of active layer was formed by spin-coating or blade-coating at ambient environment. For the spin-coating, the film was prepared at $1000 \mathrm{rpm}$ for $1 \mathrm{~min}$ in air. For the blade-coating, the silicon wafer processed by sequentially UVO treatment for $10 \mathrm{~min}$, soaking in OTS/toluene for $20 \mathrm{~min}$ and thermal annealing at $120^{\circ} \mathrm{C}$ for $20 \mathrm{~min}$ was used as the blade, and the gap between blade and substrate was $300 \mu \mathrm{m}$. The blade speed was $50 \mathrm{~mm} / \mathrm{s}$ while the temperature of substrate was $30^{\circ} \mathrm{C}$. When blade-coating, the MeTHF and MeTHF/DIO solution were stirred at $60^{\circ} \mathrm{C}$ and $\mathrm{CB}$ solution at $40^{\circ} \mathrm{C}, \mathrm{CF}$ solution at room temperature. The blade-coating was performed after the dropping of $10 \mu \mathrm{L}$ BHJ solution at the beginning of the substrate area in air. The final BHJ films were transferred in N2-filled glovebox with the followed thermal annealing at $130{ }^{\circ} \mathrm{C}$ for $10 \mathrm{~min}$. Finally, a $10 \mathrm{~nm} \mathrm{MoOx}$ and $100 \mathrm{~nm} \mathrm{Al}$ were sequentially deposited as anode below the vacuum level of $1 \times 10-4 \mathrm{~Pa}$.

\subsection{Characterizations}

The $J-V$ characteristics were performed in N2-filled glovebox under AM $1.5 \mathrm{G}\left(100 \mathrm{~mW} / \mathrm{cm}^{2}\right)$ using an AAA solar simulator (SS-F5-3A, Enli
Technology CO., Ltd.) calibrated by a standard Si photovoltaic cell with a KG5 filter. The measurements were recorded by a Keithley 2400 source meter unit at a defined device area of $4 \mathrm{~mm}^{2}$. The EQE data were obtained via using a solar cell spectral response measurement system (QE-R3018, Enli Technology CO., Ltd.) with the calibrated light intensity by a standard single-crystal Si photovoltaic cell. The film thickness was determined by a surface profilometer (Dektak XT, Bruker). The UV-Vis absorption spectra were measured on a Shimadzu UV-3600 Plus Spectrophotometer. Photoluminescence (PL) spectra were performed on PTI Quanta Master $^{\mathrm{TM}} 400$ UV/VIS Spectrofluorometer at the excitation wavelength of $590 \mathrm{~nm}$.

\subsection{Grazing incidence wide-angle X-ray scattering (GIWAXS) characterization}

GIWAXS measurements [62] were performed at beamline 7.3.3 at the Advanced Light Source. Samples were prepared on Si substrates using identical blend solutions as those used in devices. The $10 \mathrm{keV} \mathrm{X}$ ray beam was incident at a grazing angle of $0.11-0.15^{\circ}$, selected to maximize the scattering intensity from the samples. The scattered $\mathrm{x}$ rays were detected using a Dectris Pilatus $2 \mathrm{M}$ photon counting detector. In-situ GIWAXS measurements were performed at beamline 7.1 at the Stanford Synchrotron Radiation Lightsource.

\subsection{Mobility measurements}

The mobilities were measured by using space charge limited current (SCLC) model with the hole-only device of ITO/PEDOT:PSS/ PTzBI:N2200/MoOx/Al and electron-only device of ITO/ZnO/ PTzBI:N2200/Ca/Al. Hole mobility and electron mobility were obtained by fitting the current density-voltage curves and calculated by the equation $[63,64]$ :

$J=9 \varepsilon_{0} \varepsilon_{\mathrm{r}} \mu\left(V_{a p p l}-V_{b i}-V_{s}\right)^{2} / 8 L^{3}$

where $J$ is the current density, $\varepsilon_{0}$ is the permittivity of free space, $\varepsilon_{\mathrm{r}}$ is the relative permittivity of the material (assumed to be 3 ), $\mu$ is the hole mobility or electron mobility, $V_{\mathrm{appl}}$ is the applied voltage, $V_{\mathrm{bi}}$ is the built-in voltage $(0 \mathrm{~V}), V_{s}$ is the voltage drop from the substrate's series resistance $\left(V_{s}=\mathrm{IR}\right)$ and $\mathrm{L}$ is the thickness of film.

\subsection{Pseudo free-standing tensile test}

Pseudo free-standing tensile test [65] were performed at School of Polymer Science and Engineering in the University of Southern Mississippi. For the tensile testing specimen, the active layers were spincoated Si substrate covered with water soluble poly (sodium 4-styrenesulfonate) (PSS) layer $(\approx 30 \mathrm{~nm})$. The thickness of the film was measured using an interferometer (Filmetrics Inc. UVX). Then, the polymer films were etched into the dog-bone shape through an oxygen plasma etcher (Diener electronics Inc.) with a dog-bone shaped polymer etch mask then slowly dipped into a deionized water bath to release and float the dog-bone semiconducting film by dissolving the underlying water-soluble PSS layer. Specimen gripping was achieved by attaching PDMS-coated Al grips on the specimen gripping areas using van der Waals adhesion. The tensile test was performed by applying various strains to the film through a motorized linear stage equipped with a digital encoder (Micronix Inc.), while monitoring the force exerted on the film with a high-resolution load respectively cell (KYOWA Inc.)

\section{Acknowledgements}

The authors thank for the support from Ministry of Science and Technology (No. 2016YFA0200700), NSFC (21504066, 21534003, 21875182 and 21704082) and China Postdoctoral Science Foundation (2017M623162). This project was supported by the State Key 
Laboratory of Luminescent Materials and Devices of South China University of Technology. The project was supported by Open Research Fund of State Key Laboratory of Polymer Physics and Chemistry, Changchun Institute of Applied Chemistry, Chinese Academy of Sciences (201629). X-ray data were acquired at beamlines 7.3.3 and 11.0.1.2 at the Advanced Light Source, which was supported by the Director, Office of Science, Office of Basic Energy Sciences, of the U.S. Department of Energy under Contract no. DEAC02-05CH11231. The authors thank Chenhui Zhu at beamline 7.3.3, and Cheng Wang at beamline 11.0.1.2 for assistance with data acquisition.

\section{Appendix A. Supporting information}

Supplementary data associated with this article can be found in the online version at doi:10.1016/j.nanoen.2019.02.046.

\section{References}

[1] Z. He, C. Zhong, S. Su, M. Xu, H. Wu, Y. Cao, Nat. Photonics 6 (2012) 591.

[2] J. You, L. Dou, K. Yoshimura, T. Kato, K. Ohya, T. Moriarty, K. Emery, C.C. Chen, J. Gao, G. Li, Y. Yang, Nat. Commun. 4 (2013) 1446

[3] J.J.M. Halls, C.A. Walsh, N.C. Greenham, E.A. Marseglia, R.H. Friend, S.C. Moratti, A.B. Holmes, Nature 376 (1995) 498.

[4] G. Yu, J. Gao, J.C. Hummelen, F. Wudl, A.J. Heeger, Science 270 (1995) 1789.

[5] J.U. Lee, J.W. Jung, J.W. Jo, W.H. Jo, J. Mater. Chem. 22 (2012) 24265.

[6] A. Facchetti, Mater. Today 16 (2013) 123.

[7] Y.J. Hwang, B.A. Courtright, A.S. Ferreira, S.H. Tolbert, S.A. Jenekhe, Adv. Mater 27 (2015) 4578

[8] C. Lee, H. Kang, W. Lee, T. Kim, K.H. Kim, H.Y. Woo, C. Wang, B.J. Kim, Adv. Mater 27 (2015) 2466

[9] D. Mori, H. Benten, I. Okada, H. Ohkita, S. Ito, Energy Environ. Sci. 7 (2014) 2939.

[10] Y. Diao, Y. Zhou, T. Kurosawa, L. Shaw, C. Wang, S. Park, Y. Guo, J.A. Reinspach, K. Gu, X. Gu, B.C. Tee, C. Pang, H. Yan, D. Zhao, M.F. Toney, S.C. Mannsfeld, Z. Bao, Nat. Commun. 6 (2015) 7955.

[11] T. Kim, J.H. Kim, T.E. Kang, C. Lee, H. Kang, M. Shin, C. Wang, B. Ma, U. Jeong, T.S. Kim, B.J. Kim, Nat. Commun. 6 (2015) 8547.

[12] H. Yan, Z. Chen, Y. Zheng, C. Newman, J.R. Quinn, F. Dotz, M. Kastler, A. Facchetti, Nature 457 (2009) 679.

[13] B. Fan, L. Ying, P. Zhu, F. Pan, F. Liu, J. Chen, F. Huang, Y. Cao, Adv. Mater. 29 (2017) 1703906

[14] D. Chen, J. Yao, L. Chen, J. Yin, R. Lv, B. Huang, S. Liu, Z.G. Zhang, C. Yang, Y. Chen, Y. Li, Angew. Chem. Int. Ed. Engl. 57 (2018) 4580

[15] B. Fan, L. Ying, Z. Wang, B. He, X.-F. Jiang, F. Huang, Y. Cao, Energy Environ. Sci. 10 (2017) 1243

[16] L. Gao, Z.G. Zhang, L. Xue, J. Min, J. Zhang, Z. Wei, Y. Li, Adv. Mater. 28 (2016) 1884.

[17] Y. Guo, Y. Li, O. Awartani, H. Han, J. Zhao, H. Ade, H. Yan, D. Li, Adv. Mater. 29 (2017) 1700309.

[18] X. Liu, C. Zhang, C. Duan, M. Li, Z. Hu, J. Wang, F. Liu, N. Li, C.J. Brabec R.A.J. Janssen, G.C. Bazan, F. Huang, Y. Cao, J. Am. Chem. Soc. 140 (2018) 8934

[19] Z.G. Zhang, Y. Yang, J. Yao, L. Xue, S. Chen, X. Li, W. Morrison, C. Yang, Y. Li, Angew. Chem. Int. Ed. Engl. 56 (2017) 13503.

[20] J. Zhao, Y. Li, G. Yang, K. Jiang, H. Lin, H. Ade, W. Ma, H. Yan, Nat. Energy 1 (2016) 15027

[21] Z. Li, X. Xu, W. Zhang, X. Meng, W. Ma, A. Yartsev, O. Inganas, M.R. Andersson, R.A. Janssen, E. Wang, J. Am. Chem. Soc. 138 (2016) 10935.

[22] Y. Wang, Z. Yan, H. Guo, M.A. Uddin, S. Ling, X. Zhou, H. Su, J. Dai, H.Y. Woo, X. Guo, Angew. Chem. Int. Ed. Engl. 56 (2017) 15304.

[23] X. Long, Z. Ding, C. Dou, J. Zhang, J. Liu, L. Wang, Adv. Mater. 28 (2016) 6504

[24] S. Liu, Y. Firdaus, S. Thomas, Z. Kan, F. Cruciani, S. Lopatin, J.L. Bredas, P.M. Beaujuge, Angew. Chem. Int. Ed. Engl. 57 (2018) 531.

[25] S. Fabiano, C. Musumeci, Z. Chen, A. Scandurra, H. Wang, Y.L. Loo, A. Facchetti, B. Pignataro, Adv. Mater. 24 (2012) 951.

[26] C. Gu, Y. Chen, Z. Zhang, S. Xue, S. Sun, C. Zhong, H. Zhang, Y. Lv, F. Li, F. Huang, Adv. Energy Mater. 4 (2014) 1289.

[27] J.W. Jung, J.W. Jo, C.C. Chueh, F. Liu, W.H. Jo, T.P. Russell, A.K. Jen, Adv. Mater 27 (2015) 3310.

[28] D. Mori, H. Benten, I. Okada, H. Ohkita, S. Ito, Adv. Energy Mater. 4 (2014) 1301006.

[29] C. Mu, P. Liu, W. Ma, K. Jiang, J. Zhao, K. Zhang, Z. Chen, Z. Wei, Y. Yi, J. Wang,
Adv. Mater. 26 (2014) 7224

[30] R. Steyrleuthner, P.R. Di, B.A. Collins, F. Polzer, S. Himmelberger, M. Schubert, Z. Chen, S. Zhang, A. Salleo, H. Ade, J. Am. Chem. Soc. 136 (2014) 4245

[31] N. Zhou, H. Lin, S.J. Lou, X. Yu, P. Guo, E.F. Manley, S. Loser, P. Hartnett, H. Huang, M.R. Wasielewski, Adv. Energy Mater. 4 (2014) 1300785.

[32] P. Cheng, H. Bai, N.K. Zawacka, T.R. Andersen, W. Liu, E. Bundgaard, M. Jørgensen, H. Chen, F.C. Krebs, X. Zhan, Adv. Sci. 2 (2015) 1500096.

[33] H.W. Ro, J.M. Downing, S. Engmann, A.A. Herzing, D.M. Delongchamp, L.J. Richter, S. Mukherjee, H. Ade, M. Abdelsamie, L.K. Jagadamma, Energy Environ. Sci. 9 (2016) 2835.

[34] Y. Lin, C. Cai, Y. Zhang, W. Zheng, J. Yang, E. Wang, L. Hou, J. Mater. Chem. A 5 (2017) 4093.

[35] G. Giri, D.M. Delongchamp, J.A. Reinspach, D.A. Fischer, L.J. Richter, J. Xu, S.J. Benight, A.L. Ayzner, M. He, L. Fang, Chem. Mater. 27 (2015) 2350.

[36] G. Giri, E. Verploegen, S.C.B. Mannsfeld, S. Atahanevrenk, D.H. Kim, Y.L. Sang H.A. Becerril, A. Aspuruguzik, M.F. Toney, Z. Bao, Nature 480 (2011) 504.

[37] G. Giri, D.M. DeLongchamp, J. Reinspach, D.A. Fischer, L.J. Richter, J. Xu, S. Benight, A. Ayzner, M. He, L. Fang, G. Xue, M.F. Toney, Z. Bao, Chem. Mater. 27 (2015) 2350.

[38] L. Zhang, B. Lin, B. Hu, X. Xu, W. Ma, Adv. Mater. 30 (2018) 1800343.

[39] Y. Lin, S. Dong, Z. Li, W. Zheng, J. Yang, A. Liu, W. Cai, F. Liu, Y. Jiang, T.P. Russell, F. Huang, E. Wang, L. Hou, Nano Energy 46 (2018) 428.

[40] J.H. Kim, A. Nizami, Y. Hwangbo, B. Jang, H.J. Lee, C.S. Woo, S. Hyun, T.S. Kim, Nat. Commun. 4 (2013) 2520.

[41] N. Balar, Y. Xiong, L. Ye, S. Li, D. Nevola, D.B. Dougherty, J. Hou, H. Ade, B.T. O'Connor, ACS Appl. Mater. Interfaces 9 (2017) 43886

[42] W. Kim, J. Choi, J.-H. Kim, T. Kim, C. Lee, S. Lee, M. Kim, B.J. Kim, T.-S. Kim, Chem. Mater. 30 (2018) 2102.

[43] W. Lee, J.-H. Kim, T. Kim, S. Kim, C. Lee, J.-S. Kim, H. Ahn, T.-S. Kim, B.J. Kim, J. Mater. Chem. A 6 (2018) 4494.

[44] Y. Chen, P. Ye, Z.G. Zhu, X. Wang, L. Yang, X. Xu, X. Wu, T. Dong, H. Zhang, J. Hou, Adv. Mater. 29 (2017) 1603154.

[45] Y. Qin, M.A. Uddin, Y. Chen, B. Jang, K. Zhao, Z. Zheng, R. Yu, T.J. Shin, H.Y. Woo, J. Hou, Adv. Mater. 28 (2016) 9416.

[46] A.K. Kyaw, D.H. Wang, V. Gupta, W.L. Leong, L. Ke, G.C. Bazan, A.J. Heeger, Acs Nano 7 (2013) 4569.

[47] M.A. Uddin, T.H. Lee, S. Xu, Y.P. Song, T. Kim, S. Song, T.L. Nguyen, S. Ko, S. Hwang, Y.K. Jin, Chem. Mater. 27 (2015) 5997.

[48] L. Yang, S. Zhang, H. Chang, J. Zhang, H. Yao, Y. Yang, Z. Yun, W. Zhao, J. Hou, J. Am. Chem. Soc. 139 (2017) 1958.

[49] M. Lenes, M. Morana, C.J. Brabec, P.W.M. Blom, Adv. Funct. Mater. 19 (2010) 1106

[50] J.L. Wu, F.C. Chen, Y.S. Hsiao, F.C. Chien, P. Chen, C.H. Kuo, M.H. Huang, C.S. Hsu, Acs Nano 5 (2011) 959.

[51] J.A. Bartelt, D. Lam, T.M. Burke, S.M. Sweetnam, M.D. Mcgehee, Adv. Energy Mater. 5 (2015) 1500577.

[52] S. Chen, Y. Liu, L. Zhang, C. Pcy, Z. Wang, G. Zhang, W. Ma, H. Yan, J. Am. Chem. Soc. 139 (2017) 6298.

53] E.H.M. Han, L.E. Govaert, Prog. Polym. Sci. 30 (2005) 915.

[54] S. Wu, Polymer 28 (1987) 1144.

[55] T.F. O'Connor, A.V. Zaretski, B.A. Shiravi, S. Savagatrup, A.D. Printz, M.I. Diaz D.J. Lipomi, Energy Environ. Sci. 7 (2013) 370.

[56] S. Savagatrup, A.D. Printz, T.F. O'Connor, A.V. Zaretski, D.J. Lipomi, Chem. Mater 26 (2014) 3028

[57] J. Rivnay, S.C. Mannsfeld, C.E. Miller, A. Salleo, M.F. Toney, Chem. Rev. 112 (2012) 5488.

[58] R. Steyrleuthner, R. Di Pietro, B.A. Collins, F. Polzer, S. Himmelberger, M. Schubert, Z. Chen, S. Zhang, A. Salleo, H. Ade, A. Facchetti, D. Neher, J. Am. Chem. Soc. 136 (2014) 4245.

[59] R. Steyrleuthner, M. Schubert, I. Howard, B. Klaumunzer, K. Schilling, Z. Chen, P. Saalfrank, F. Laquai, A. Facchetti, D. Neher, J. Am. Chem. Soc. 134 (2012) 18303.

[60] X. Gu, H. Yan, T. Kurosawa, B.C. Schroeder, K.L. Gu, Y. Zhou, J.W.F. To, S.D. Oosterhout, V. Savikhin, F. Molina-Lopez, C.J. Tassone, S.C.B. Mannsfeld, C. Wang, M.F. Toney, Z. Bao, Adv. Energy Mater. 6 (2016) 1601225.

[61] Y. Sun, J.H. Seo, C.J. Takacs, J. Seifter, A.J. Heeger, Adv. Mater. 23 (2011) 1679

[62] A. Hexemer, W. Bras, J. Glossinger, E. Schaible, E. Gann, R. Kirian, A. MacDowell, M. Church, B. Rude, H. Padmore, J. Phys. Conf. Ser. 247 (2010) 012007.

[63] S. Chen, Y. Liu, L. Zhang, P.C.Y. Chow, Z. Wang, G. Zhang, W. Ma, H. Yan, J. Am. Chem. Soc. 139 (2017) 6298.

[64] J.A. Bartelt, D. Lam, T.M. Burke, S.M. Sweetnam, M.D. McGehee, Adv. Energy Mater. 5 (2015) 1500577.

[65] S. Zhang, M.U. Ocheje, S. Luo, D. Ehlenberg, B. Appleby, D. Weller, D. Zhou, S. Rondeau-Gagne, X. Gu, Macromol. Rapid Commun. (2018) e1800092. 